Al-Qadisiyah Journal of Pure Science Vol.(26) Issue (3) (2021) pp. Bio 1-8

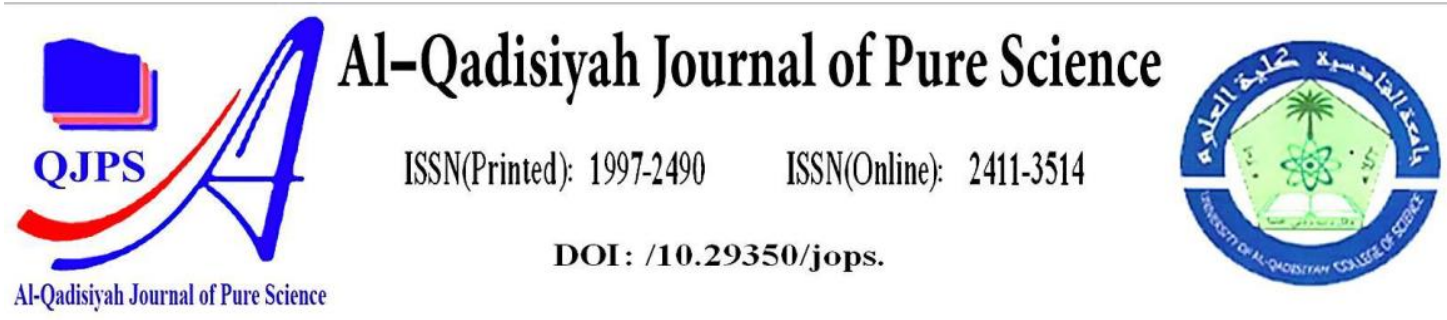

\title{
Larvicidal Effect of Secondary Metabolites of Three (Diptera:Culicidae) Fungi against Cx.quinquefasciatus
}

\begin{tabular}{|c|c|}
\hline Authors Names & ABSTRAC \\
\hline $\begin{array}{l}\text { Ali A. H. Abdul AL Ameer } \\
\text { Article History } \\
\text { Received on: } 3 / 5 / 2021 \\
\text { Accepted on: 6/6/2021 } \\
\text { Keywords: } \\
\text { V.lecanii, P. chrysogenum } \\
\text { and A. niger, Filaria } \\
\text { vectors, Secondary } \\
\text { metabolites, Larvicidal } \\
\text { activity. } \\
\text { DOI: } \\
\text { https://doi.org/10.29350/ } \\
\text { jops.2021.26. 3.1322 }\end{array}$ & $\begin{array}{l}\text { The larvicidal effect of secondary metabolites of Verticillum } \\
\text { lecanii,Pencillium chrysogenum and Aspergillus niger against filaria } \\
\text { vector Cx.quinquefasciatus was investigated. efficacies have been tested } \\
\text { at four different concentrations of secondary metabolites of mentioned } \\
\text { fungi }(25,50,75,100) \text { ppm .larvicidal efficacy demonstrates that larval } \\
\text { mortality was related to concentration, exposure time and larval age. } \\
\text { Higher mortality was observed at high concentration, moreover mortality } \\
\text { increased when exposure time increased, additionally, the older larvae } \\
\text { were more resistant to fungal filtrate. Also, it was perceptible that larvae } \\
\text { of Cx.quinquefasciatus have a chieved higher mortality for V.lecanii, at } \\
\text { the concentration (100ppm )after } 24,48 \text {, and } 72 \text { hrs for first instars were } \\
\text { (90\%,96.66\%, and } 100 \%) \text { respectively, while for fourth instars } \\
\text { were }(76.66 \%, 86.66 \% \text {,and } 93.33 \%) \text { respectively in the same concentration } \\
\text { and time, while P. chrysogenum achieved higher mortality but lower than } \\
\text { V.lecanii for first instars were }(76.66 \%, 83.33 \%, 90 \%) \text { respectively, at the } \\
\text { concentration }(100 \text { ppm) and the same time, and its a chieved lower } \\
\text { mortality for fourth instars were } 60 \%, 70 \% \text {, and } 80 \%) \text { respectively in the } \\
\text { same concentration and time of exposure, moreover A. niger recorded } \\
\text { lower mortality than both V.lecanii and P. chrysogenum when it a } \\
\text { chieved higher mortality for first instars were }(63.33 \%, 76.66 \% \text {, and } 83 \text {. } \\
33 \%) \text { respectively at the higher concentration and same exposure time } \\
\text { and its a chieved lower mortality for fourth instars } \\
\text { were(36.66\%,56.66\%,and70\%) respectively in the same concentration } \\
\text { and time of exposure. These findings were clearly significant and } \\
\text { enhanced that secondary metabolites of V.lecanii, P. chrysogenum and } \\
\text { A. niger were fatal and can be used as, larvicide, as safer alternative to } \\
\text { insecticides against Filaria vectors. }\end{array}$ \\
\hline
\end{tabular}




\section{1-Introduction:}

The mosquito Culex quinquefasciatus is the main carrier of elephantiasis, which it causes byWuchereria bancrofti, and it is one of the diseases that cause very large deaths, more than 120 million people are infected with this disease and 40 million are handicapped and invalids(WHO,2013). on the other hand, this mosquito is an efficient vector for encephalitis, to control the disease is either to eliminate the pathogen or the vector, and that the latter is easier to control. The reliance on chemical mosquito control mainly led to the emergence of many problems such as:

Resistance to chemical pesticides and toxic effects in the biological enemies of pests and the effect of toxin residues on plant crops and the cumulative effect of pesticides on human health and environmental pollution, in addition to an increase production costs. Some of the entomopathogenic fungi have achieved remarkable success in the field of microbial control of mosquitoes such as the fungus (Couch) Lagenidium giganteum, Leptolegnia chapmanii (Seymour), Crypticola clavulifera (Humber) (Class: Oomycetes), and Coelomomyces spp(Class: Chytridiomycetes and others. V.lecanii, it is anamorphic fungus one of the Ascomycota genera belongs to the order Hypocreales and highly pathogenic, while the $P$. chrysogenum and A. niger belongs to the order Eurotioales. However, in Iraq as the author aware,the larvicidal efficacy of these three fungi have been received little concern and the present research focus on new results on pathogenicity of these fungi because they are environmentally friendly, not coasted and more effective.

-Materials and methods: 2

Samples collection site:

Astagnant ponds was choosed for larvae collection. The larvae of $C x$.quinquefasciatus collected by Long-arm scoops were placed in plastic bottles, and they were taken to the laboratory and these bottles were emptied into basin and which were covered with muslin[19].

\section{Isolate of fungi}

The fungal isolate were previously isolated from larvae cadaver of Culex quinquefasciatus and the culture kept of mycology lab[2].

\section{Identification of fungi:}

The fungi were identificated according to the key of classification.[7].

\section{Permanent culture for Mosquito: $C x$. quinquefasciatus:}

Culture of $C x$. quinquefasciatus established according to[8].

Preparation of secondary metabolites for fungi $V$. lecanii, $P$. chrysogenum, A. niger: (SDB) Sabouraud dextrose broth was prepared and distributed into a (250) ml flask of (150) $\mathrm{ml}$ flask and inoculate the medium with $0.5 \mathrm{~cm}$ diameter discs from the aforementioned fungi culture at 7 days old and separately. The flasks were incubated at a temperature of $2 \mp 25 \mathrm{C}^{0}$ for two weeks, after which they were filtered using a filter paper (Whatman No. 1) with a Buechner funnel and with the help of a vacuum pump and re-filtered using a millipore filters $(0.22 \mu)$. To sterilize the secondary metabolites from potentially contaminated bacteria present four concentrations were prepared 25ppm, 50ppm, 75ppm, 100ppm [17].

\section{Bioassy for various concentrations of $V$. lecanii, P. Chrysogenum} and $A$.niger:

40 larvae were taken from each of the four instars, which were prepared for each concentration of secondary metabolites concentrations, each fungus tested, and distributed to four containers three of these containers, each one containing $(100 \mathrm{ml})$ of each concentration 
of the concentrations, while the fourth container contains sterile distilled water only (Control) for a period of two minutes, then the treated larvae were transferred with

a soft brush to glass containers of $(250 \mathrm{ml})$ capacity containing sterile distilled water, to which the larvae food was added at a rate of $10 \mathrm{mg} / \mathrm{ml}$. After that, the containers were placed in the incubator and incubated at atemperature $2 \mp 25 \mathrm{C}^{0}$ and a light period of $14: 10$ (L/D) hours. Then the mortality ratio was calculated within $24,72,96$ hours of treatment [18] and the values were corrected according to Orell and Schneider equation [1].

\section{Statistical analysis:}

Mortality percentages were computed and adjusted by Abbott's formula Statistical analysis of the experimental data was performed to find the significance between the concentration of secondary metabolite and mortality at different periods with different secondary metabolite using spss programme General Line Model with using F-test, in 0.05 significance level $(\mathrm{p}<0.05)[5]$.

\section{3-Results:}

The table(1) shows the effect of the secondary metabolites of fungus $V$. lecanii, on the larval instars of Cx.quinquefasciatus, at the concentration $25 \mathrm{ppm}$ of $V$. lecanii achieved mortality rates were $(40 \%, 36.66 \%, 33.33 \%$ and $30 \%)$ for four larval instars, after 24 hours of treatment, subsequently the highest percentage of mortality was $100 \%$ for the first and second larval instars, (96\% and 93.33\%) for the third and fourth larval instars after 72 hours of treatment at $100 \mathrm{ppm}$. An increase in the mortality rate of larval stages was observed with an increase concentration when the concentration of $V$. lecanii was $(50 \mathrm{ppm})$ the mortality rates for four instars were $(63.33 \%, 60 \%, 56.66 \%, 50 \%)$ respectively at the $24 \mathrm{hrs}$ and these mortality rates increased to reached

$(86.66 \%, 76.66 \%, 73.33 \%, 70 \%)$ respectively when the concentration increased to reached $(75 \mathrm{ppm})$ in same instars and period. This indicates that there is a direct relationship between the concentrations used and the exposure time on the one hand and the mortality rates for the four instars on the other hand. The mortality rates increased with the increase in concentration and duration of exposure when using the secondary metabolites of $V$. lecanii, for example the mortality rates were $(90) \%$ respectively after $48 \mathrm{hrs}$ at the concentration(75ppm) for second instar when the concentration increased to reached (100ppm) and the duratuion of exposure become (72)hrs the mortality rates were $(100) \%$ respectively in the same instar. The results show an inverse relationship between larva age and mortality rates, so the greater the age of the larva, the lower the mortality rates of $V$. lecanii, for example, when exposing the larval instars to the fungal filtrate of at the highest concentration after 72 hours, the mortality rates for the four larval instars were, in order (100\%) (100\%) (96.66\%) $(93.33 \%)$.

Table(1)effect of different concentrations of secondary metabolites of fungus $V$. lecanii on the larval instars of the Cx.quinquefasciatus

\begin{tabular}{|c|c|c|c|c|}
\hline \multirow{3}{*}{ Instar } & \multirow{3}{*}{$\begin{array}{c}\text { Concentration } \\
\text { PPM }\end{array}$} & \multicolumn{3}{|c|}{ Larval mortality\% } \\
\hline & & \multicolumn{3}{|c|}{ V. lecanii } \\
\hline & & 24 & 48 & 72 \\
\hline \multirow[b]{3}{*}{ First } & 25 & 40 & 63.33 & 73.33 \\
\hline & 50 & 63.33 & 80 & 90 \\
\hline & 75 & 86.66 & 93.33 & 96.66 \\
\hline
\end{tabular}




\begin{tabular}{|c|c|c|c|c|}
\hline & 100 & 90 & 96.66 & 100 \\
\hline & control & $\mathbf{0}$ & 0 & 0 \\
\hline \multirow{5}{*}{ Second } & 25 & 36.66 & 56.66 & 70 \\
\hline & 50 & 60 & 73.33 & 83.33 \\
\hline & 75 & 76.66 & 90 & 96.66 \\
\hline & 100 & 86.66 & 93.33 & 100 \\
\hline & control & $\mathbf{0}$ & 0 & $\mathbf{0}$ \\
\hline \multirow{5}{*}{ Third } & 25 & 33.33 & 50 & 60 \\
\hline & 50 & 56.66 & 66.66 & 80 \\
\hline & 75 & 73.33 & 83.33 & 86.66 \\
\hline & 100 & 83.33 & 86.66 & 96.66 \\
\hline & control & $\mathbf{0}$ & $\mathbf{0}$ & $\mathbf{0}$ \\
\hline \multirow{5}{*}{ Forth } & 25 & 30 & 43.33 & 60 \\
\hline & 50 & 50 & 66.66 & 76.66 \\
\hline & 75 & 70 & 83.33 & 86.66 \\
\hline & 100 & 76.66 & 86.66 & $\mathbf{9 3 . 3 3}$ \\
\hline & control & $\mathbf{0}$ & $\mathbf{0}$ & $\mathbf{0}$ \\
\hline
\end{tabular}

LSD at 0.05 significance level of interference $=11.104$

Table (2) shows the mortality rates of the four larval instars at the lowest concentration, which is $25 \mathrm{ppm}$, and it were, in order, $(30,26.66,26.66,23.33) \%$ after 24 hours, while the mortality rates at the highest concentration of $100 \mathrm{ppm}$ were in the following order $(76.66,73.33,73.33,60) \%$ for the same instars and duration.It was observed in the fungus Penicillium chrysogenum the same that occurred in the fungus Verticillum lecanii in relation of increasing mortality rates by increasing concentration on the one hand and increasing the duration of exposure on the other hand, as well as the inverse relationship between larva age and mortality rates.

Table(2)effect of different concentrations of secondary metabolites of fungus $P$. chrysogenum on the larval instars of the Cx.quinquefasciatus

\begin{tabular}{|c|c|c|c|c|}
\hline \multirow{3}{*}{ Instar } & \multirow{3}{*}{$\begin{array}{c}\text { Concentration } \\
\text { PPM }\end{array}$} & \multicolumn{3}{|c|}{ Larval mortality\% } \\
\hline & & \multicolumn{3}{|c|}{ P. chrysogenum } \\
\hline & & 24 & 48 & 72 \\
\hline \multirow{7}{*}{ First } & 25 & 30 & 46.66 & $\mathbf{5 3 . 3 3}$ \\
\hline & 50 & 43.33 & 60 & 76.66 \\
\hline & 75 & 66.66 & 80 & 86.66 \\
\hline & 100 & 76.66 & 83.33 & 90 \\
\hline & control & $\mathbf{0}$ & $\mathbf{0}$ & $\mathbf{0}$ \\
\hline & 25 & 26.66 & 40 & $\mathbf{5 3 . 3 3}$ \\
\hline & 50 & 43.33 & 56.66 & 66.66 \\
\hline
\end{tabular}




\begin{tabular}{|c|c|c|c|c|}
\hline \multirow{3}{*}{ Second } & 75 & 56.66 & 70 & 80 \\
\hline & 100 & 73.33 & 83.33 & 86.66 \\
\hline & control & 0 & 0 & 0 \\
\hline \multirow{5}{*}{ Third } & 25 & 26.66 & 36.66 & 46.66 \\
\hline & 50 & 40 & $\mathbf{5 3 . 3 3}$ & 63.33 \\
\hline & 75 & 60 & 70 & 80 \\
\hline & 100 & 73.33 & 76.66 & 83.33 \\
\hline & control & $\mathbf{0}$ & $\mathbf{0}$ & $\mathbf{0}$ \\
\hline \multirow{5}{*}{ Forth } & 25 & 23.33 & $\mathbf{3 3 . 3 3}$ & 46 \\
\hline & 50 & 36.33 & 53.33 & 60 \\
\hline & 75 & 50 & 66.66 & 73.33 \\
\hline & 100 & 60 & 70 & 80 \\
\hline & control & $\mathbf{0}$ & 0 & 0 \\
\hline
\end{tabular}

LSD at 0.05 significance level of interference $=\mathbf{1 1 . 1 0 4}$

Table(3) explain that the mortality rates were in the following order(26.66,23.33,20,16.66)\% for the four instars and at the lowest concentration, which is $25 \mathrm{ppm}$ after 24 hours of treatment ,and mortality rates were in the following order(63.33,43.33,40,36.66)\% at the highest concentration, which is $100 \mathrm{ppm}$ in same instars and period .Also a positive relationship was observed through an increase in the rates of mortality rates with an increase in concentration on the one hand and an increase in the duration of exposure on the other hand ,as well as an inverse relationship between the age of the larva and the rates of mortality, as happened in the fungus V.lecanii.

Table(3)effect of different concentrations of secondary metabolites of fungus $A$. niger on the larval instars of the Cx.quinquefasciatus

\begin{tabular}{|c|c|c|c|c|}
\hline \multirow{3}{*}{ Instar } & \multirow{3}{*}{$\begin{array}{c}\text { Concentration } \\
\text { PPM }\end{array}$} & \multicolumn{3}{|c|}{ Larval mortality\% } \\
\hline & & \multicolumn{3}{|c|}{ A. niger } \\
\hline & & 24 & 48 & 72 \\
\hline \multirow{5}{*}{ First } & 25 & 26.66 & 30 & 46.66 \\
\hline & 50 & $\mathbf{3 3 . 3 3}$ & $\mathbf{5 3 . 3 3}$ & 63.33 \\
\hline & 75 & 56.66 & 66.66 & 80 \\
\hline & 100 & 63.33 & 76.66 & 83.33 \\
\hline & control & $\mathbf{0}$ & $\mathbf{0}$ & $\mathbf{0}$ \\
\hline \multirow{8}{*}{ Second } & 25 & 23.33 & 26.66 & 40 \\
\hline & 50 & 26.66 & 50 & 56.66 \\
\hline & 75 & 36.66 & 63.33 & 73.33 \\
\hline & 100 & 43.33 & 70 & 76.66 \\
\hline & control & $\mathbf{0}$ & $\mathbf{0}$ & $\mathbf{0}$ \\
\hline & 25 & 20 & 23.33 & 36.66 \\
\hline & $\mathbf{5 0}$ & 23.33 & 46.66 & $\mathbf{5 3 . 3 3}$ \\
\hline & 75 & 30 & 56.66 & 70 \\
\hline
\end{tabular}




\begin{tabular}{|c|c|c|c|c|}
\hline \multirow{3}{*}{ Third } & 100 & 40 & 60 & 73.33 \\
\cline { 2 - 5 } & control & 0 & 0 & 0 \\
\hline \multirow{4}{*}{ Forth } & 25 & 16.66 & 20 & 33.33 \\
\cline { 2 - 5 } & $\mathbf{5 0}$ & 26 & 43.33 & 50 \\
\cline { 2 - 5 } & 75 & 36.66 & 56.66 & 70 \\
\cline { 2 - 5 } & 100 & 0 & 0 & 0 \\
\hline
\end{tabular}

LSD at 0.05 significance level of interference $=\mathbf{1 1 . 1 0 4}$

\section{4-Discussion :}

Table shows the superiority of the fungus $V$. lecanii by increasing its effect on the mortality rates of the four larval instars after treatment $(48,72,96)$ hours. While P.chrysogenum had a greater effect on mortality rates than A.niger of four larval instars. The use of secondary metabolites of fungi pathogenic to mosquitoes is more effective than the use of the fungal suspension against mosquito larvae. This is what the two researchers [14] explained when they found that these products have the ability to reduce the number of larvae for a period of two months if used on a pond or swamp. It should be noted that the relationship between each of the secondary metabolites concentrations and the duration of exposure on the one hand and the mortality rates on the other hand is similar to what happened when using the fungal suspension. The present results of the secondary metabolites are in agreement with the findings [10]when they used a concentration of $20 \mathrm{mg} / \mathrm{ml}$ of the crude extract of Beauvercin produced by $B$. bassiana against the larvae of mosquitoes Ae. aegypti, resulting in its mortality by (86\%) after 48 hours from the exposure period, but when the crude extract was used for the compound(Tolypin) the product from the fungus Tolypocladium niveum (100 $\mathrm{mg}$ / 1) against the larvae of both mosquitoes Cx pipiens and An. maculipennis [20] obtained a mortality rate of $100 \%$ due to the accumulation of hydrogen compounds in the cell mass of the pathogen to give this pathogen a potential virulence as an insecticide[15]. The use of secondary metabolites of the fungi Trichophyton ajelloi and C. lobtum against the larvae of the mosquitoes of Cx.quinquefasciatus and An. stephensi was more effective on the first larval instar than the rest of the

instars and in both species [11][13]. A. flavus is the most pathogenic

fungus of mosquito larvae Cx.quinquefasciatus, this is what the researcher has shown [9]through its greater effect on the third larval instar of other used fungi such as (T. viride, $F$. vasinfectum, $P$. falitum, and A. parasiticus), this instar mentioned by the researcher indicated that $A$. flavus has a high toxic effect through its secretion of aflatoxin toxins. The effect of the metabolites of $F$. oxysporium on the first and fourth instars larvae of An. stephensi and $C x$. quinquefasciatus The pathogenicity of seven genera of $C$. pseudomerdarium, A. niger, P.chrysogenum, A. fumigatus, A. flavus and $O$. verruculatum, and found that fungus $T$. ajelloi was the most pathogenic due to the high mortality of the larvae of the Cx.quinquefasciatus mosquito. [16] when first instar larvae of An. stephensi and Cx.quinquefasciatus raw secondary metabolites of $M$. anisoplia, with a concentration of (100\%), the mortality rate was $(100 \%)$ and $(96.66 \%)$ for both types, respectively. The current results are in agreement with the results of [17]. Previously, when treated with the fungal suspension[6]. First instar larvae mortality was (100\%) for mosquitoes An. Pulcharrhimus and (96.66\%) mosquito larvae Cx.quinquefasciatus when using a concentration $(100 \%)$ of the raw secondary metabolites of L. lundbergii, this is what he obtained [3]. The secondary metabolites of C. keratinophilum had a significant effect on the three larval instars of the Cx.quinquefasciatus mosquito, while on the fourth instar larvae their effect was little, this was confirmed. 
[4]. The fourth larval instar of the Cx.quinquefasciatus mosquito were the most sensitive instar of the secondary metabolites of Verticillum lecanii. This is what they found[8], as their results differed from the previously mentioned results.

\section{5-References:}

[1] Abbot , W. (1925). A method of computing the effectiveness of insecticide . J. Econ. Entomol. $18: 265-267$.

[2] Weiser,J. and Matha,V. (1988).Tolypin, a new insecticidal metabolite of fungi of the genus Tolypocladium. J. Invertebr Pathol. 51:94-96.

[3] Al-Karawi, Hanaa Rahman Lafta (2012). A laboratory study of the efficiency of some control methods in two types of mosquitoes(Diptera:Culicidae )in Diwaniyah Governorate. Master thesis. Faculty of Science / University of Al-Qadisiyah 94 pages.

[4] Al-mashkoor, Baraa Jalil Saeed (2014). Evaluation of some of the agents of bacterial control. Culex quinquefasciatus (Diptera: culicidae)

Master Thesis, Faculty of Science / Al-Qadisiyah University. 64 pages.

[5] Alrawi, Khashi Mahmoud and Abdul aziz Khalaf Allah (1992), Design and Analysis of Experiments Agricultural, Dar Al Kotob for Printing and Publishing, University of Mosul.

[6] Balachander, M.;Remadevi, O.K.; Sasidharan, T.O and Bai, N.S.(2012).Virulence and mycotoxic effects of Metarhizium anisopliae on Mahogany shoot borer, Hypsipyla robusta (Lepidoptera:pyralidea). Journal of Forestry Research.23(4):651-659.

[7] Ellis , D.; Davis , S.; Alexiou, H.; Hondke , R. and Bartley , R. (2007). Descriptions of medical fungi. second edition . University of Adelaide . AUSTRALIA: 204pp.

[8] Gerberg ,E.J.; Barnard, D.R.;and Ward, R.A.; (1994). Manual for Mosquito Rearing and Experimental Techniques. American Mosquito Control Association Bulletin . 5: 61-62 .

[9] Govindarajan, M.; Jebanesan, A.;and Reetha, D.; (2005) .Larvicidal effect of extracellular secondary metabolites of different fungi against the mosquito, Culex quinquefasciatus Say. Trop Biomed .22(1):1-3.

[10] Grove , J.F.; and Pople , M.;(1980) . The insecticidal activity of Beauveria and enniation complex . Mycopathology .70:103- 105.

[11] Mohanty and Prakash, (2002). Efficacy of Chrysosporium lobatum against larvae of malaria vector, Anopheles stephensi in the laboratory.Curr Sci.83:1585-1588.

[12] Mohanty and Prakash,(2010) .Comparative efficacy and pathogenicity of keratinophilic soil fungi against Culex quinquefasciatus larvae.Indian J Microbiol.50 :299-302.

[13] Mohanty, Suman Sundar; Prakash( 2004 ).Extracellular metabolites of Trichophyton ajelloi against Anopheles stephensi and Culex quinquefasciatus larvae Curr Sci. 86:323-325.

[14] Mohanty, S. S. and Prakash.(2000) Laboratory evaluation of Trichophyton ajelloi, a fungal pathogen of Anopheles stephensi and Culex quinquefasciatus. Journal of the American Mosquito Control Association 16(3): 254- 257. 
[15] Nisbet, L.J.; and Fox, F.M. (1991).The Biodiversity of Microorganisms and Invertebrates: Its Role In Sustainable Agriculture. London: CAB International.p. 445-650.

[16] Prakash, Singh, Soni, N.and Sharma, S.(2010). Pathogenicity of Fusarium oxysporum against the larvae of Culex quinquefasciatus (Say) and Anopheles stephensi (Liston) in laboratory. Parasitol Res .107(3): 651-655.

[17] Singh and Prakash (2010). Fungi Beauveria bassiana (Balsamo) metabolites for controlling malaria and filarial in tropical countries. Advan. in Biomed. Res.9: 238-242.

[18] Soni and Prakash (2011). Aspergillus niger Metabolites Efficacies Against the Mosquito Larval (Culex quinquefasciatus, Anopheles Stephensi and Aedes Aegypti) Population after Column Chromatography. American Journal of Microbiology . (1): 15-20 .

[19] Soni and Prakash (2012). Larvicidal effect of Verticillium lecanii metabolites on Culex quinquefasciatus and Aedes aegypti larvae. Asian Pacific Journal of Tropical Disease .

2(3):220-224. 